\title{
A UTILIZAÇÃO DA ANÁLISE MULTICRITÉRIO NO SOFTWARE DINÂMICA EGO PARA DEFINIÇÃO DE ÁREAS FAVORÁVEIS PARA O CULTIVO DO MOGNO AFRICANO (KHAYA IVORENSIS) NO ESTADO DE MINAS GERAIS
}

\author{
Laylla Gabrielle Borges Correia*
}

\section{Resumo}

O presente trabalho objetiva apresentar subsídios para a primeira etapa da análise de áreas favoráveis para o cultivo do Mogno Africano (Khayaivorensis) no Estado de Minas Gerais, com base na aplicação da Análise de Multicritério, na plataforma DINÂMICA EGO, de forma a fornecer subsídios técnicos para produção sustentável de madeira, no que concerne à aptidão da terra para seu plantio. A seleção de áreas favoráveis para o cultivo do Mogno Africano em Minas Gerais se dá através da reunião de variáveis ambientais para o cultivo bem sucedido, tais como: temperatura, precipitação, pedologia, hidrografia, topos de morro, nascentes, vegetação, Unidades de Conservação em comum acordo com a legislação ambiental. Neste trabalho são apresentados os cenários de aptidão da espécie considerando apenas as variáveis "precipitação" e "temperatura do ar" a título de comprovação da aplicabilidade da técnica utilizada.

Palavras-chave:Análise Multicritério, Favorabilidade, Cultivo, Mogno Africano.

\begin{abstract}
This paper aims to contribute for favorable areas analysis for the cultivation of African Mahogany (Khayaivorensis) in the State of Minas Gerais, based on the application of Multicriteria Analysis in DINAMICA EGO platform in order to provide subsidies technicians for sustainable timber production, regarding the suitability of the land for its cultivation. The selection of favorable areas for the African Mahogany cultivation in Minas Gerais is through meeting environmental variables for successful cultivation, such as temperature, precipitation, soil science, hydrology, hilltops, springs, vegetation, protected areas in agreement with the environmental legislation. This paper presents scenarios fitness of the species considering only the variables "precipitation" and "air temperature" by way of proving the applicability of the technique used.
\end{abstract}

Key-words:Multicriteria Analysis, favorable areas for cultivation, African Mahogany.

\footnotetext{
*Mestranda em Análise e Modelagem de Sistemas Ambientais pelo IGC/UFMG.layllambiental@gmail.com.br 


\section{1- INTRODUÇÃO}

O Brasil produz aproximadamente 25 milhões de metros cúbicos de madeiras tropicais em toras e consome 13 milhões de metros cúbicos de madeira serrada, o que o torna líder mundial de produção e consumo no setor (ITTO, 2007 apud ALMEIDA, A. N. de. et al., 2008).

Entretanto, de acordo com a Lei de Crimes Ambientais de 1998 (Lei 9.605), a produção ilegal de madeira é crime, com penas que variam de 6 meses a 5 anos de prisão e multas elevadas. Ainda assim, a exploração criminosa de madeira continuou ocorrendo em larga escala devido à frágil aplicação da Lei e à demanda contínua do mercado. O baixo índice de condenações e a responsabilização reduzida dos infratores só perpetuaram a sensação generalizada de impunidade (GREENPEACE BRASIL, 2005).

Casos recorrentes nesse sentido têm ocorrido com frequência na região amazônica, onde estudos indicam que a maioria da produção madeireira daquela região é considerada predatória ou oriunda de desmatamento e que, da produção dita sustentável, grande parte advinha de planos de manejo deficientes (BARRETO et al., 2002).

Para o Brasil se manter em longo prazo entre os líderes do mercado internacional de madeira, faz-se necessário ter-se a garantia de um nível de produção mais estável, buscando, cada vez mais, atender às exigências do mercado internacional, inclusive quanto aos preços e às exigências ambientais, por um lado, e, por outro, garantir condições de renovação adequada das condições ambientais, da produção e os devidos benefícios sociais para a região (ALMEIDA et al, 2010).

Dentre as espécies brasileiras mais cobiçadas mundialmente encontra-se o mogno (Swieteniamacrophylla King), de modo que o seu “[...] valor comercial extraordinário [...] tem estimulado a sua extração na Amazônia Brasileira há muitos anos, mas com maior intensidade desde o inicio dos anos 70" (GROGAN et al, 2002, apud PINHEIRO, 2011, p. 11). Os estoques naturais dessa madeira encontram-se no extremo sul do Pará, sudeste do Amazonas e Acre, que são áreas de enorme pressão exploratória, o que levou os órgãos ambientais brasileiros a reduzirem as cotas de exportação desde 1990, proibindo a liberação de novos 
planos de manejo desde 1995 e o transporte, processamento e comercialização da espécie, após detectar práticas ilegais no Pará, em 2001 (PINHEIRO et al, 2011).

Nesse cenário (PINHEIRO et al, 2011), uma das alternativas para garantia do mogno (brasileiro) como patrimônio natural renovável é a substituição dessa madeira, em suas mais diversas aplicações, por outras espécies, cujas características se assemelhem àquela. Nesse sentido, vem sendo muito estudado o potencial do Mogno Africano (Khayaivorensis), por tratar-se de madeira nobre e de rápido crescimento que pode se plantar, em alguns sítios, até mesmo concomitante com o próprio mogno nativo (gênero Swietenia). São também normalmente resistentes à ação da broca do ponteiro (HypsipylagrandellaZeller), causadora de danos ao mogno nativo.

Por tratar-se de espécie exótica, sua cultura requer tratamento diferenciado em relação às nativas; a comercialização da madeira é garantida e atinge preços elevados no mercado nacional e internacional, com preços muitas vezes acima daqueles praticados pela venda do mogno nacional, tornando-se um bom investimento em médio prazo. Ademais, o Mogno Africano vem demonstrando adaptar-se muito bem às condições climáticas do Brasil (PINHEIRO et al, 2011).

Também podem ser citados alguns benefícios socioambientais (PINHEIRO et al, 2011), como a utilização e um melhor aproveitamento das áreas já tradicionalmente usadas para a monocultura de outras espécies, como o ordenamento da expansão da cultura em áreas cujas restrições ecológicas e normativas exigem um maior controle com relação à inserção de espécies exóticas. No aspecto socioeconômico, sua cultura pode perfeitamente ser associada a programas e ações ligadas à geração de renda, tanto durante a produção quanto após o ciclo da cultura. Ainda segundo Pinheiro et al. (2011), as experiências já em curso no Brasil especialmente em Minas Gerais - vêm demonstrando que é possível realizar plantios mistos com esta espécie, sejam elas exóticas ou nativas. Sugerem-se algumas espécies de boa produção de madeira para fazer consórcio com a Khaya, tais como o Jacarandá-da-Bahia, Peroba Rosa e, ou Cedro Australiano, Eucalyptus.

Para tanto, o estudo e identificação de áreas potencias para o plantio do Mogno Africano no Brasil, sobretudo no estado de Minas Gerais, torna-se um aliado para tomada de decisão por parte dos empresários, consumidores e demais interessados, levando-se em consideração os diversos fatores que podem favorecer ou dificultar tal plantio em áreas específicas. 
A seleção de áreas favoráveis para o cultivo da espécie torna-se uma ferramenta fundamental para a criação de mecanismos de orientação à implementação de determinada cultura numadada área. Através de tal seleção, é possível identificar, caracterizar e delinear cartograficamente unidades ambientais reconhecíveis na paisagem natural, classificadas em função da aptidão para o cultivo sustentável de determinada espécie. Desta forma, deve ser obrigatoriamente confrontada a informação sobre as exigências ecofisiológicas da espécie e sobre a oferta ambiental da área onde se pretende implantá-la (EMBRAPA, 2010).

\section{2.- A ESPÉCIE KHAYA IVORENSIS}

O Mogno Africano (Kayaivorensis), pertence à família Meliaceae A. juss., subfamília III, SWIETENIOIDEAE, Tribo 2, SWIETENIEAE e gênero Khaya.

Trata-se de árvore sempreverde ou decídua (PINHEIRO, 2011, pg.31) e ocorre naturalmente segundo Lamprecht (1990) e Lemmens (2008), em regiões tropicais úmidas, de baixa altitude, da África Ocidental. Possivelmente, também ocorre na Guiné, Libéria, na República Central da África e no Congo. Além disso, esta espécie é bastante plantada dentro da sua área natural de distribuição bem como na Ásia e América Tropicais.

Em seu habitat natural é uma árvore de grande porte, podendo atingir de 40 a $60 \mathrm{~m}$ de altura e diâmetro a altura do peito de 2,10 m (DAP). Seu Tronco é retilíneo, algumas vezes um pouco sinuoso, apresentando fuste comercial livre de ramificações até $30 \mathrm{~m}$ de altura, base com grandes sapopemas ${ }^{1}$ que se elevam cerca de $4,0 \mathrm{~m}$, sobretudo nas árvores mais velhas, algumas vezes estendendo raízes de superfície proeminentes.

Possui casca escura a marrom, ligeiramente áspera ou salpicada, de depressões superficiais causadas pela queda de placas quase circulares, espessa e de coloração marromavermelhada ou marrom-alaranjada, sabor amargo. Casca interna cuja coloração vai de rosa a avermelhada. Vale salientar que fora de seu habitat natural tem apresentado grande rugosidade, causada provavelmente, por agentes abióticos ainda desconhecidos. A casca é amarga e largamente empregada na medicina tradicional. A decocção da casca é tomada para tratar tosses, febres e anemias e é aplicada externamente em feridas, lesões, arranhões, úlceras e tumores. Como analgésico, pode ser utilizada para tratar dores reumáticas. Quanto à raiz, sua polpa é utilizada para tratar problemas de disenteria. Brotos novos esmagados e folhas são

\footnotetext{
${ }^{1}$ Raízes que se desenvolvem com o tronco de muitas árvores, formando em volta dele divisões achatadas. 
aplicadosexternamente, como analgésico. Também as sementes podem ser usadas na produção de sabão.

A madeira, por sua vez, é altamente valorizada pela indústria moveleira, trabalhos de marcenaria, caixas e estojos decorativos, compensados, laminados, e comumente utilizada para molduras de janelas, painéis, portas e escadas. É adequada para construções leves, assoalhos leves, construção de navios e embarcações, canoas escavadas, corpos de veículos, cabos, instrumentos esportivos e musicais, brinquedos, inovações, instrumentos de precisão, entalhes, torneados, escadas e polpa de celulose. E ainda é utilizada na produção do carvão e ainda aproveitada como lenha.

A espécie foi introduzida no Brasil em 1973, no estado do Pará, com umas poucas sementes provenientes da Costa do Marfim, pela Embrapa Amazônia Oriental ${ }^{2}$. De início foram produzidas seis mudas, que logo se tornaram matrizes da maioria dos plantios hoje existentes (PINHEIRO et al, 2011. p. 51).

No Brasil, os estudos para introdução da espécie são relativamente recentes e não há experimentos conduzidos para obtenção de dados mais consistentes. Entretanto, segundo a Associação Brasileira dos Produtores de Mogno Africano (ABPMA) existem 3.009,7 ha da espécie plantados no Brasil pelos seus associados, sendo 2.707,7 em Minas Gerais, sendo os plantios mais antigos aqueles ocorridos há oito anos (Instituto Brasileiro de Florestas - IBF) por pequenos, médios e grandes produtores. A área de plantio por produtor varia de dois a 516 ha, segundo dados cadastrados pela ABPMA até o ano de 2012. Ainda não houve colheita da madeira para fins comerciais haja vista que se levam, em média, 17 anos para o corte final.

\section{3- MANEJO E DESEMPENHO ECONÔMICO E AMBIENTAL DO MOGNO AFRICANO}

A Khayaivorensis pode ser propagada por sementes, sendo que 1.000 sementes pesam entre 130 a $310 \mathrm{~g}$. A temperatura ótima para o armazenamento das mesmas é de $3^{\circ} \mathrm{C}$, enquanto o teor de umidade é de 6\%. A germinação é lenta, durando até 40 dias, sendo alta a taxa de viabilidade das sementes quando usadas frescas e saudáveis; no entanto, após três meses, a viabilidade das sementes é de apenas 5\% (PINHEIRO et al, 2011, p. 39). Além disso, aaplicação de $0,5 \mathrm{~g}$ de N-P-K por muda é recomendada, não excluindo-se a necessidade de

\footnotetext{
${ }^{2}$ Empresa Brasileira de Pesquisa Agropecuária Amazônia Oriental. 
realização de uma análise química do solo em questão (PINHEIRO et al, 2011, p. 40). Outra forma de propagação da espécie está relacionada à propagação vegetativa, ou clonagem através da técnica de estaquia e por fim através de plantio de mudas comuns.

Quanto ao manejo, sabe-se que o primeiro desbaste em um plantio de 1.000 árvores /ha precisa ser feito quando elas atingem $15 \mathrm{~m}$ de altura e $15 \mathrm{~cm}$ de DAP para uma densidade entre 400 e 500 árvores/ha. O segundo desbaste ou raleamento pode ser feito quando as árvores estiverem com $20 \mathrm{~m}$ de altura e $20 \mathrm{~cm}$ de diâmetro, para 200 a 250 árvores/ha. $\mathrm{O}$ terceiro desbaste com $25 \mathrm{~m}$ de altura e $25 \mathrm{~cm}$, para 125 a 150 árvores/ha e, por fim, o quarto, a $30 \mathrm{~cm}$ de diâmetro para 75 a 100 árvores/ha (PINHEIRO et al, 2011, p. 45).

No que diz respeito às florestas plantadas em geral ${ }^{3}$, o Brasil possui potencial para se consolidar como um dos maiores produtores mundiais do setor. No entanto, para que isso aconteça é necessário que sejam proporcionadas condições para a indústria nacional manter- se competitiva e diversificada. Ainda, segundo a ABRAF, em relação ao setor florestal, o país precisa aproveitar de maneira eficaz seu potencial e para isso precisa levar em consideração as principais barreiras que atrapalham o avanço setorial, tais como: licenciamento ambiental burocrático, infraestrutura deficitária e precária, entre outros (ABRAF, 2013, p. 30).

No que diz respeito à Khayaivorensis, as perspectivas são positivas (PINHEIRO et al., 2011, p. 62): o Brasil tem observado um aumento de renda familiar, com o consequente aumento do consumo de artigos de luxo, em que a madeira se encaixa. Além disso, com a queda da bolsa de valores em 2008, houve desvalorização, dentre as commodities, da madeira de eucalipto e carvão, ao passo que as madeiras nobres - caso da Khayaivorensis- mantiveramse inalteradas. Ainda, segundo Pinheiro et al. (2011), o mercado do Mogno Africano é seguro, pois já é consagrado internacionalmente. Seu rendimento líquido em ha/ano chega a R \$23.267,70 (PINHEIRO, A.L., et al., 2011, p. 63).

\section{4 - CRITÉRIOS DE SELEÇÃO DE ÁREAS ADEQUAdAS PARA O CULTIVO dO MOGNO AFRICANO}

A seleção de áreas favoráveis para o cultivo do Mogno Africano em Minas Gerais se dá através da reunião de variáveis ambientais para o cultivo bem sucedido da espécie, tais como:

\footnotetext{
${ }^{3}$ Anuário Estatístico/2013, da ABRAF/Associação Brasileira de Produtores de Florestas Plantadas. 
temperatura, precipitação, pedologia, hidrografia, topos de morro, nascentes, vegetação e Unidades de Conservação em comum acordo com a legislação ambiental.

Neste trabalho, porém, são apresentadas conclusões concernentes à Análise Multicritério considerando apenas as variáveis precipitação e temperatura do ar, haja vista a necessidade de se aplicar a metodologia selecionada a priori bem como avaliar sua funcionalidade e resultados em face ao objetivo da seleção de áreas favoráveis para o plantio da Khaiaivorensis no Estado de Minas Gerais.

A geotecnologia, enquanto conjunto de tecnologias para coleta, processamento e análise de informações georreferenciadas, tem papel fundamental para viabilizar a tomada de decisão seja ela de cunho público ou particular em vertentes tão distintas quanto multidisciplinares.

O primeiro passo foi elaborar um banco de dados que consiste em mapas temáticos de variáveis de interesse. Tal procedimento se deu em ambiente ArcGis e as variáveis coletadas para todo estado com as respectivas fontes, constam na tabela a seguir (TAB.1):

Tabela 1 - Fonte de dados físicos - Minas Gerais

\begin{tabular}{|l|l|}
\hline Mapa & Fonte \\
\hline Precipitação & World Clim \\
\hline Hidrografia & Instituto Mineiro de Gestão das águas (IGAM) \\
\hline Pedologia & Universidade Federal de Viçosa \\
\hline Temperatura & World Clim \\
\hline Vegetação & Zoneamento Ecológico Econômico (ZEE MG) \\
\hline Unidade de Conservação & Zoneamento Ecológico Econômico (ZEE MG) \\
\hline
\end{tabular}

Fonte: Elaborada pela autora, 2013.

Uma vez elaborado o banco de dados e já sabido as exigências climáticas da espécie, definiu-se no software Dinâmica EGO, um processo que combinasse e transformasse dados espaciais em uma resposta para uma futura tomada de decisão quanto ao local favorável de plantio - através do cruzamento dos dados espaciais para delimitação da aptidão da cultura no estado-. 
Vale salientar que a sigla do software designa Environmental for GeoprocessingObjects - Ambiente para Objetos Geoprocessáveis. O software contém uma série de algoritmos chamados funtores, que são capazes de realizar operações distintas, incluindo simulações espaciais, transição e métodos de calibração e validação de modelos. O software favorece simplicidade, flexibilidade e desempenho (SOARES-FILHO B. S. et al., 2011).

A tabela a seguir (TAB.2) apresenta as variáveis necessárias para obtenção dos resultados esperados, ressaltando-se que apenas as variáveis em negrito fazem parte da análise do presente trabalho:

Tabela 2 - Critérios de análise multicritério para identificação de áreas favoráveis para o cultivo do Mogno Africano - Minas Gerais

\begin{tabular}{|c|c|c|}
\hline Variáveis & Classificação & Critério \\
\hline Temperatura média anual & Apta a 27 ${ }^{\circ} \mathbf{C}$ \\
\hline Solo & Apto & $\begin{array}{c}\text { LATOSSOLO VERMELHO-AMARELO } \\
\text { ARGISSOLO VERMELHO-AMARELO }\end{array}$ \\
\hline Precipitação média & Apta & 1600 e 2500 mm \\
\hline Declividade & Restrita & Acima de $45^{\circ}$ \\
\hline Altitude & Restrita $1.800 \mathrm{~m}$ \\
\hline Vegetação & Restrita & Unidades de conservação \\
Área de Proteção Permanente (APP)
\end{tabular}

Fonte: Elaborada pela autora, 2013.

\subsection{Critérios de avaliação física}

Estes critérios contribuem para tomada de decisão no que concerne ao melhor custobenefício de forma a selecionar espaços territoriais que apresentam as melhores condições climáticas e pedológicas para cultivo da espécie em questão. Ressalta-se novamente que apenas as variáveis temperatura média anual (subitem 4.1.1.) e precipitação média anual (subitem 4.1.3.) são objetos do presente trabalho.

\subsubsection{Temperatura média anual}

Segundo PINHEIRO, A. L. et al (2011), o Mogno Africano da espécie Khayaivorensis, ocorre naturalmente em sítios onde a temperatura varia entre 18 e $27^{\circ} \mathrm{C}$.

\subsubsection{Pedologia}


Esta espécie prefere solos com reduzida capacidade de retenção de água (LAMPRECHT, 1990 apud PINHEIRO, 2011), mas não tolera longos períodos de solo seco. A espécie necessita basicamente de radiação solar, água e nutrientes. O tipo de solo para seu melhor desenvolvimento são solos de meia encosta. Na zona da mata mineira, a espécie desenvolve muito bem nos latossolos vermelho-amarelos e nos argissolos vermelho-amarelos. É necessário evitar solos compactados ou adensados, como o latossolo amarelo coeso (PINHEIRO, A.L., et al).

Os solos devem ser profundos, pois, solos rasos com algum impedimento físico, como rochas ou camadas adensadas pode prejudicar o bom desenvolvimento da espécie. Além disso, devem ser evitados elevados teores de alumínio no solo. (PINHEIRO, A. L. et al, 2011).

\subsubsection{Precipitação média anual}

PINHEIRO, A.L, et al (2011) afirma que os espécimes são bem sucedidos em florestas higrófilassubcaducifólias de baixas altitudes precipitação média entre 1600 e $2500 \mathrm{~mm}$ e suporta período seco de no máximo 4 meses, ocorrendo assim, de forma dispersa. Vale salientar, no entanto, que em períodos chuvosos a Khayaivorensis suporta inundações, se mostrando resistentes.

\subsubsection{Declividade}

São consideradas APPs todas as terras cuja declividade sejam superiores a $45^{\circ}$, tornando-se então um critério restritivo a ser utilizado quando da Análise Multicritério com todas as variáveis.

\subsubsection{Altitude}

São consideradas APPs todos as terras cujas altitudes sejam superiores a $1.800 \mathrm{~m}$, portanto outro critério restritivo.

\subsubsection{Unidades de conservação}

Trata-se de um critério de exclusão identificado através da Base de Dados do Zoneamento Ecológico Econômico do Estado de Minas Gerais. Compõem áreas de preservação ambiental, onde não podem ser realizadas intervenções inclusive no que tange ao cultivo de espécie exótica. 


\subsection{7. Áreas de Preservação Permanente (APPs)}

Essa variável, embora de importância categórica, acredita-se ser o maior desafio, pois não há base de dados para o Estado em virtude da grande complexidade de sua formação. $O$ processo utilizado na Dinâmica EGO e supra mencionado é denominado Análise de Multicritério (AMC), que é indicado quando procura-se resolver questões que envolvem vários critérios de avaliação (JALES, L.F. et al, 2013).

\section{5- A PERTINÊNCIA DA ANÁLISE DE MULTICRITÉRIO, NA PLATAFORMA DINÂMICA EGO, tendo em vista a seleção de áreas potencialmente adequadas para o cultivo do Mogno Africano em Minas Gerais}

A AMC trata-se de uma ferramenta matemática que permite comparar diferentes alternativas (ou cenários), fundamentada em vários critérios, com o objetivo de direcionar os tomadores de decisão para uma escolha ponderada (Roy, 1996 apud FREITAS, M. I. C.).

Malczewski (2006) comentou que, em muitas das aplicações de SIG na área de análise ambiental, é comum o envolvimento de múltiplos critérios para se atender a um ou mais objetivos. Problemas de decisão espacial normalmente envolvem grande conjunto de alternativas viáveis e múltiplas em ambiente SIG (SARTORI, A. A. C., 2012).

Alguns estudiosos empregaram a AMC em ambiente SIG para subsidiar a tomada de decisão como o caso de Sartori et al (2011) que buscavam gerar um mapa de áreas prioritárias à recomposição florestal com o intuito de conservar recursos hídricos. Wang e Medley (2004) utilizaram a AMC para identificação de áreas apropriadas à restauração florestal em Ohio,EUA, com relação ao seu potencial para conservação de carbono. Ferraz e Vettorazzi (2003) utilizaram o método para identificação de áreas apropriadas à recomposição florestal, com espécies nativas, em fazendas de reflorestamentos, com base em princípios de ecologia da paisagem, entre outros (SARTORI, A. A. C., 2012).

A AMC pode ser realizada de diversas formas, sendo muito utilizada aquela por meio da Combinação Linear Ponderada (CLP) e a Média Ponderada Ordenada (MPO). A primeira consiste resumidamente em uma multiplicação de cada mapa de critério, isto é, multiplicação de cada célula ou pixel de cada mapa pelo seu peso (SARTORI et al, 2012, p. 1082). No presente trabalho, os mapas de critérios consistem no mapa de temperatura e de precipitação de Minas Gerais, obtido do World Clim (1950- 2000). 
Uma forma de definir pesos dos fatores é a aplicação da Técnica Participatória desenvolvida por Eastman (2001), Malczewski (1999), Chen et al. (2000) e Valente (2005) que consiste na reunião e consulta a especialistas de diferentes áreas de interesse do trabalho (SARTORI A. A. C. et al., p. 1082, 2012).

Entretanto, esta técnica não foi utilizada neste trabalho haja vista que os limites mínimos e máximos sugeridos para cultura em questão, estavam descritos em bibliografia produzida por especialistas: PINHEIRO et al., 2011.

Assim sendo, a AMC no DINAMICA EGO combina e transforma dados espaciais em uma resposta única através, neste caso, de sobreposição / multiplicação de mapas. Foi desenvolvido um modelo através do qual fossem selecionados no estado de Minas Gerais, somente os sítios que possuíssem (considerando a base de dados históricos) temperatura entre 18 e $27^{\circ} \mathrm{C}$ e precipitação média anual entre 1.600 a $2.500 \mathrm{~mm}$.

\section{6- DISCUSSÃO E RESULTADOS}

É sabido que a Análise Multicritério realizada neste trabalho não é suficiente para tomada de decisão quanto ao local ideal para plantio do Mogno Africano considerando as condições naturais, pois, representa a parte minoritária dos quesitos/critérios exigidos para um resultado satisfatório.

Todavia, o objetivo do trabalho não consiste em apresentar tais resultados, mas sim, comprovar a aplicabilidade do método para futura realização de seleção de áreas favoráveis, considerando então, todos os critérios que subsidiem tal decisão. Os Mapas 1 e 2 apresentam respectivamente, a média anual de precipitação no Estado de Minas Gerais tendo como fonte de dados o World Clim cujo tamanho das células equivalem a 500 e as áreas selecionadas pelo software Dinamica EGO, cujos valores de precipitação encontram-se dentro do limite de favorabilidade para a cultura em questão. 
Mapa 1 - Média Anual Precipitação de MG

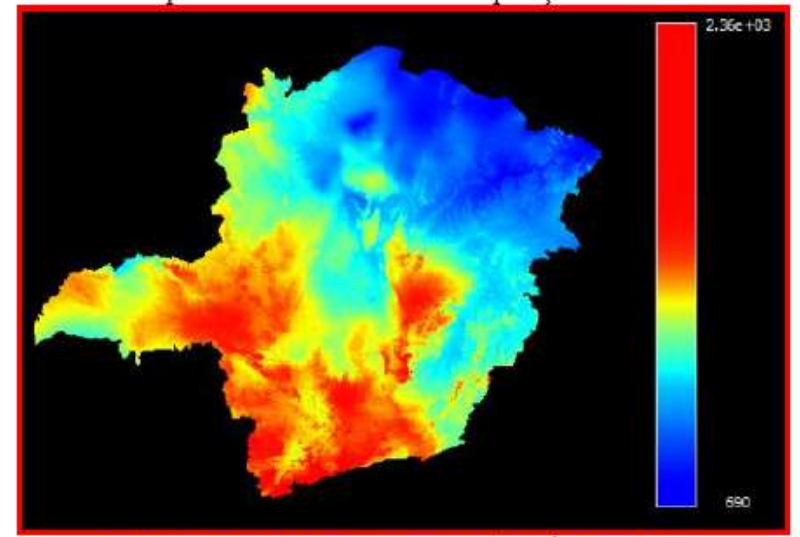

Fonte: WORLD CLIM, 1950-2000 / DINÂMICA EGO

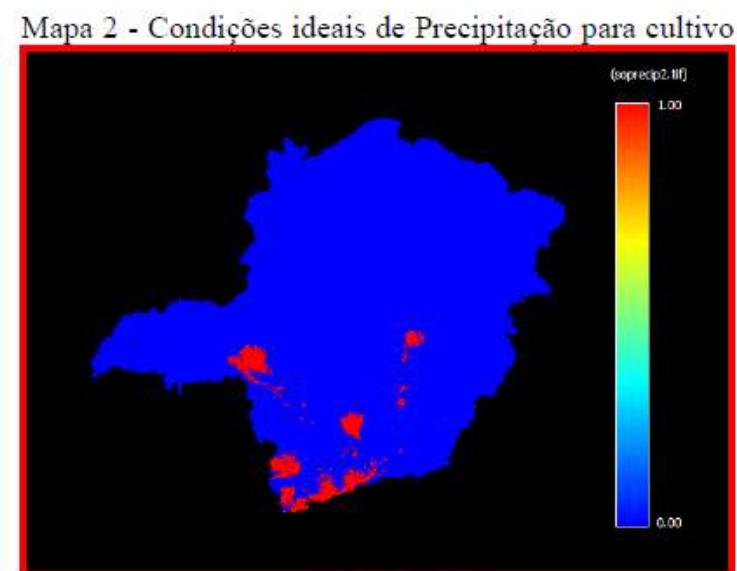

Fonte: DINÂMICA EGO

As manchas em vermelho no Mapa 2 representam as áreas em que naturalmente poderia se plantar o Mogno Africano, caso a precipitação fosse a única variável que subsidiasse tal decisão. Isto é, nestas manchas, encontram-se sítios que possuem precipitação média anual (considerando uma série histórica de 1950 a 2000) entre 1.600 e $2.500 \mathrm{~mm}$.

Os Mapas 3 e 4 apresentam respectivamente, a média anual de temperatura no Estado de Minas Gerais tendo como fonte de dados o World Clim cujo tamanho das células equivalem a 500 e as áreas selecionadas pelo software Dinamica EGO, cujos valores de temperatura encontram-se dentro do limite de favorabilidade para a cultura em questão.

Mapa 3 - Temperatura de Minas Gerais

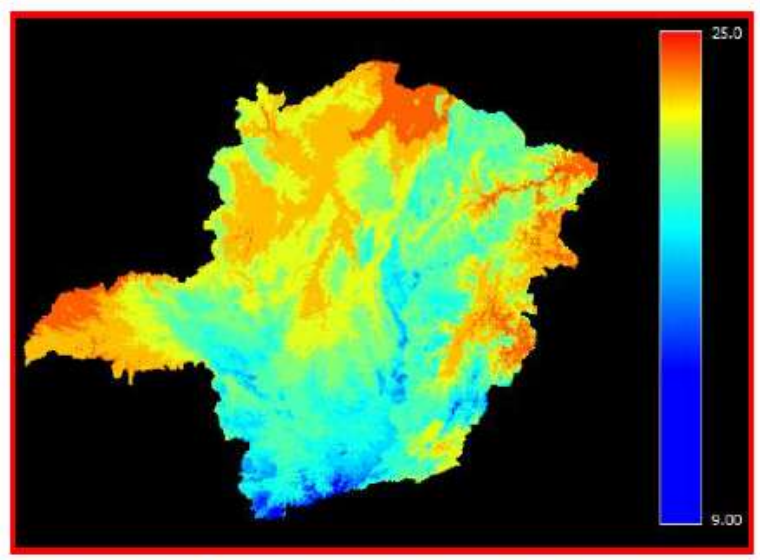

Fonte: WORLD CLIM, 1950-2000 / DINÂMICA EGO, 2013.
Mapa 4 - Condições ideais de Temperatura

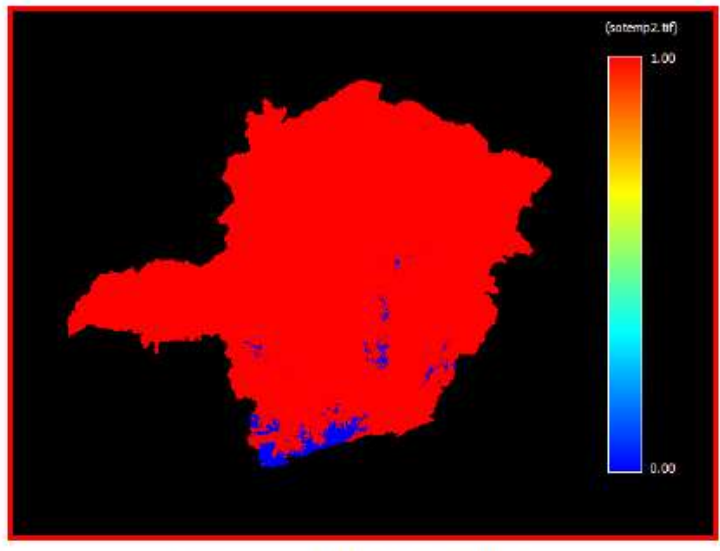

Fonte: DINÂMICA EGO, 2013.

As manchas em vermelho representam as áreas em que naturalmente poderia se plantar o Mogno Africano, caso a temperatura fosse a única variável que subsidiasse tal decisão. Isto é, nestas manchas, encontram-se sítios que possuem temperatura média anual (considerando uma série histórica de 1950 a 2000) entre 18 e $27^{\circ} \mathrm{C}$. 
É de fácil percepção, que quanto maior o intervalo das exigências climáticas, maior então a área de interesse, haja vista a extensão territorial e mudanças climáticas decorrentes de relevo, umidade, vegetação entre outros aspectos que interferem na formação de tais dados climáticos. Visualiza-se no Mapa 3, que a grande maioria do Estado encontra-se dentro da faixa de limites de temperaturas naturalmente ideais para cultivo da espécie Khayaivorensis. Isto, devese ao intervalo bastante flexível e suficientemente grande entre 18 e $27^{\circ} \mathrm{C}$.

Por fim, o Mapa 5 apresenta a sobreposição ou multiplicação dos dois mapas supracitados.

\section{Mapa 5 - Condições ideais de Temperatura x Precipitação}

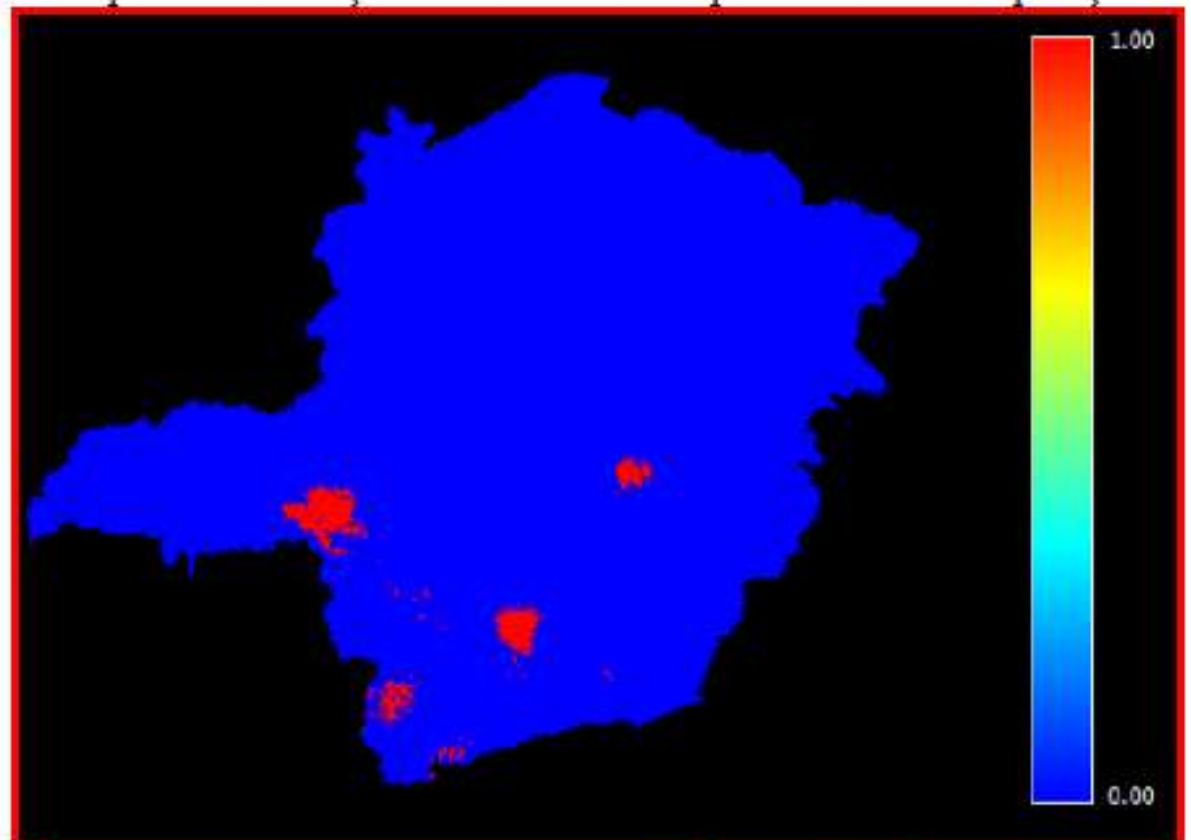

Fonte: AMC no software DINÂMICA EGO, 2013.

Quando se reúnem os dois aspectos em um único trato, verifica-se a diminuição considerável de áreas aptas para o plantio da espécie Khayaivorensis, o que justifica uma análise mais extensa e complexa, considerando os demais critérios, inclusive levando em consideração a qualidade e resolução dos dados. Embora o procedimento tenha sido realizado apenas para duas variáveis, foi possível apurar o quão satisfatório o Método de Análise Multicritério se apresenta para o objetivo de seleção de áreas aptas física e legalmente para o cultivo sustentável do Mogno Africano (Khayaivorensis), em sua forma mais complexa no que tange ao número de variáveis envolvidas. 
Cabe salientar que esta metodologia bem como o modelo elaborado pode ter múltiplas aplicações, entre elas: definição de áreas mais adequadas para, instalação de empreendimentos, análise de risco ambiental, análise de sensibilidade ambiental e planejamento de uso das terras. Sugere-se a realização de inferências quanto à agregação das demais variáveis bem como questões inerentes ao melhor custo-benefício quanto à compra de terra e plantio da espécie. Para o presente, deu-se como satisfatório o resultado obtido, mostrando que é possível aplicar a técnica de Análise Multicritério para a implementação do modelo final.

Por fim, ratifica-se o quanto é importante o método ser claro e aplicável em outros modelos. Além disso, uma questão crucial para avaliação de resultados obtidos relaciona-se com a qualidade dos dados utilizados. 


\section{REFERÊNCIAS}

ALMEIDA, A. N. de. et al. Mercado de madeiras tropicais: substituição na demanda de exportação. In: ACTA Amazônica. [S.1.].2008. Disponível em <http://www.scielo.br/pdf/aa/v40n1/v40n1a15.pdf>. Acesso em: 09 out. 2013.

ASSOCIAÇÃO BRASILEIRA DOS PRODUTORES DE MOGNO AFRICANO (ABPMA). BARRETO, P et al, 2002. Controle do desmatamento da exploração de madeira na Amazônia: diagnóstico e sugestões. Relatório Técnico do IMAZON - Versão preliminar para discussão. MMA/PPG7/ProManejo. Belém. 36 pp. apud ALMEIDA, A. N. de et al. Tropical sawnwood market: substitution export demand. Disponível em: <http://dx.doi.org/10.1590/S004459672010000100015>. Acesso em: 07 de set. 2012.

EMPRESA BRASILEIRA DE PESQUISA AGROPECUÁRIA. CENTRO NACIONAL DE PESQUISA DE SOLOS MINISTÉRIO DA AGRICULTURA PECUÁRIA E ABASTECIMENTO. Zoneamento Agroecológico do Dendezeiro para as Áreas Desmatadas da Amazônia Legal. Rio de Janeiro, Abril, 2010. Disponível em <http://www.cnps.embrapa.br/zoneamento_dende/ZonDende.pdf>. Acesso em 05 set. 2012.

FREITAS, M. I. C. Análise em SIG Multicritério. Disponível em: $<$ http://www.rc.unesp.br/igce/planejamento/download/isabel/geopr_prog_engamb/Aula13 _ea/multicriterio.pdf>. Acesso em: 01 nov. 2013.

GREENPEACE. TOLERÂNCIA ZERO: CHEGA DE MADEIRA ILEGAL Porque a exploração de madeira na Amazônia está fora de controle. Disponível em: www.greenpeace.org/brasil/Global/brasil/report/2007/6/greenpeacebr_060525_amazonia_re latorio_tolerancia_zero_port_v.1.p. Acesso em 05 nov 2013.

International Tropical Timber Organization(ITTO). 2007. Annual review and assessment of the world timber situation. Yokohama, (Document GI-7/07). 53 pp. apud ALMEIDA, A. N. de. et al. Mercado de madeiras tropicais: substituição na demanda de exportação. In: ACTA Amazônica. [S.1.].2010. Disponível em <http://www.scielo.br/pdf/aa/v40n1/v40n1a15.pdf>. Acesso em: 09 out. 2013.

JALES, L. F. et al. Análise multicritério para definição de áreas prioritárias para implantação de projeto de Pagamento por Serviços Ecossistêmicos no município de Brumadinho, MG. Anais XVI Simpósio Brasileiro de Sensoriament Remoto - SBSR, Foz do Iguacu,PR, Brasil,13 a18 de abril de 2013, INPE. Disponível em: <http://www.dsr.inpe.br/sbsr2013/files/p1185.pdf >. Acesso em: 15 out. 2013. LAMPRECHT, H. Silvicultura nos trópicos. Eschborn: (GTZ) Gmbh. [Trad. De Guilherme de Almeida Sedas e Gilberto Calcagnotto], 1990. 343 p.

LEMMENS, R. H. M. J., 2008. Khayaivorensis A. Chev. [Internet] Record from Protabase. Louppe, D., Oteng-Amoako, A. A.and Brink, M. (Editors). PROTA (Plant Resources of Tropical Africa/Ressources vegetables de I'Afriquetropicale), Wageningen, Netherlands. <http:77database.prota.org/search.htm>. Acessed: 19 nov. 2009.

MALCZEWSKI, J. GIS-based multicriteria decision analysis: a survey of the literature. International Journal of Geographical Information Science, v.20, n.7, p.703-726, 2006.

PINHEIRO, A. L. et al. Ecologia, silvicultura e tecnologia de utilização dos Mognos Africanos (Khaya spp.). Viçosa. 2011. 
SARTORI, A. A. C. et al, Combinação linear ponderada na definição de áreas prioritárias à conectividade entre fragmentos florestais em ambiente SIG, 2012. Revista Árvore, Viçosa-MG, v.36, n.6, p.1079-1090, 2012 Disponível em: http://www.scielo.br/scielo.php?pid=S01007622012000600009\&script=sci_arttext. Acesso em: 29 out. 2013.

SOARES-FILHO B. S. et al., 2009. Modeling Environmental Dynamics withDinamica EGO. Disponível em: $<$ http://www.csr.ufmg.br/dinamica/tutorial/Dinamica_EGO_guidebook.pdf $>$.Acesso em: 10 set. 2013

WORD CLIM - Global Climate Data - Freeclimate data for ecologicalmodelingand GIS. Disponível em: www.wordclim.org/current. Acesso em 13 out 2013. 